\title{
Espacio, tiempo y paisaje. La representación de procesos y experiencias visuales en el análisis, el proyecto y la planificación de los espacios abiertos
}

\author{
Space, Time and Landscape. \\ Representation of processes and visual experiences in the \\ analysis, design and planning of open spaces
}

\section{Resumen}

Javier Pérez-Igualada jperezi@urb.upv.es

Gonzalo Vicente-Almazán gvicente@urb.upv.es

Departamento de Urbanismo. Escuela Técnica Superior de Arquitectura. Universidad Politécnica de Valencia.

España

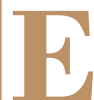
propósito de este trabajo es el de examinar la relación entre espacio, tiempo y paisaje desde dos perspectivas diferentes aunque complementarias, la de la percepción y la del proyecto. Por un lado, se analiza el modo en que se representan las secuencias visuales en el análisis de los espacios abiertos, trasladando al campo del paisaje la perspectiva espaciotemporal que Giedion introdujo para la arquitectura en su influyente libro Espacio tiempo y arquitectura. Por otro, se estudian los sistemas de representación en e proyecto de los procesos de transformación del paisaje, desde los asociados a la sucesión vegetal a los de carácter más estructural, que trascienden la escala del diseño de base arquitectónica para situarse en el campo del plan estratégico de escala urbana.

Palabras clave: espacio-tiempo, análisis paisajístico, diseño del paisaje, representación del paisaje, urbanismo paisajista.

\section{Abstract:}

The purpose of this paper is to examine the relationship between space, time and landscape from two different but complementary approaches: that of perception and that of project. On the one hand, the way in which visual sequences are represented in the analysis of open spaces is analyzed, transferring to the field of landscape the space-time approach that Giedion introduced for architecture in his influential book Space, Time and Architecture. On the other hand, representation systems to design landscape transformation processes are studied, from those associated with plant succession to those of a more structural nature, which transcend the scale of architectural design to be placed in the field of urban scale strategic plans.

Keywords: space-time, landscape analysis, landscape design, landscape representation, landscape urbanism. 
1. Introducción. La presencia del tiempo en los espacios abiertos: percepción y proyecto

La cuestión de la relación entre espacio, tiempo y paisaje puede abordarse desde dos perspectivas complementarias que están vinculadas a la percepción y al proyecto, a los lugares existentes y a los ideados.

Desde un punto de vista perceptual, el tiempo está asociado a su vez a dos tipos de experiencias visuales del paisaje, en función del tipo de mirada, fija o en movimiento. La más sencilla es la que corresponde a la mirada fija, en la que el observador contempla el paisaje y los cambios que en él se producen desde un único punto de vista fijo. La mirada en movimiento, en cambio, es una experiencia más compleja, en la que el observador se desplaza por el interior de los espacios verdes, y contempla desde puntos de vista variables tanto los elementos inertes o estables del paisaje como los vivos y cambiantes. Estas experiencias visuales se traducen en experiencias estéticas que, además de vivirse, pueden ser objeto de representación.

Desde un punto de vista proyectual, por otro lado, el tiempo está asociado a la gestión desde el diseño de los ciclos estacionales y los procesos naturales que afectan a los elementos vivos del paisaje, como el material vegetal. Gestión, en este caso, significa voluntad propositiva aplicada a parámetros cambiantes.

La aproximación perceptual es de tipo analítico, y supone una exploración sensorial de los espacios verdes existentes, de los cambios que se producen en ellos y de las sucesivas secuencias visuales que se van generando al recorrerlos. El tiempo se traduce en una sucesión de perspectivas.

La aproximación proyectual tiene un objetivo muy diferente: idear un espacio verde todavía inexistente. Es una aproximación desde el diseño, en la que el tiempo es un elemento de composición más, debido a que el proyecto del paisaje no es un proyecto de objetos o formas acabadas, sino un proyecto de procesos, entre los que ocupa un papel central la sucesión vegetal.

Examinaremos a continuación por separado la relación entre espacio, tiempo y paisaje desde estas dos perspectivas, la perceptual y la proyectual ${ }^{1}$.

${ }^{1}$ Morán (2014) ha propuesto un listado de sistemas de representación del proyecto paisajista contemporáneo, a los que denomina "morfologías del cambio". Algunos de estos sistemas se examinan también en nuestro trabajo, aunque estructurados de un modo diferente, como consecuencia del enfoque dual adoptado, que diferencia entre percepción y proyecto.

\section{La aproximación perceptual al espacio-tiempo: secuencias visuales y perspectiva}

"L'oeil crée la perspective, la marche la fait vivre"2. Esta frase de André Le Nôtre está grabada en una losa de piedra del suelo, junto a uno de los estanques del eje central de los jardines de Vaux-le-Vicomte, obra maestra del paisajismo clásico francés del siglo XVII.

La frase de Le Nôtre denota una posición frente a la percepción visual de los espacios abiertos que no puede considerarse estática, sino que resulta, de hecho, más bien cercana a la idea contemporánea de espacio-tiempo que Sigfried Giedion identificó como característica de cubismo y de la arquitectura moderna en su influyente libro Espacio, tiempo y Arquitectura, publicado en $1941^{3}$.

Para Giedion la visión en perspectiva renacentista, como concepto universal vigente en la cultura occidental durante cinco siglos, era solamente el punto de partida para una revolución que tendría lugar como resultado del concepto de espacio-tiempo. Con la revolución artística de principios del siglo XX surgieron otros planteamientos respecto a la perspectiva, nuevas formas de concebirla basadas en una mirada diferente y cambiante, realizada no desde un punto de observación fijo sino desde uno en movimiento (Bigas, Bravo y Contepomi, 2010).

Una secuencia de vistas exteriores de la Bauhaus de Dessau muestra con claridad el concepto de espaciotiempo de Giedion, asociado en este caso a la percepción de un objeto arquitectónico diseñado en base a una composición de volúmenes centrífuga, basada en un equilibrio asimétrico, que se va descubriendo progresivamente al no privilegiar ningún punto de vista concreto (Figura 1).

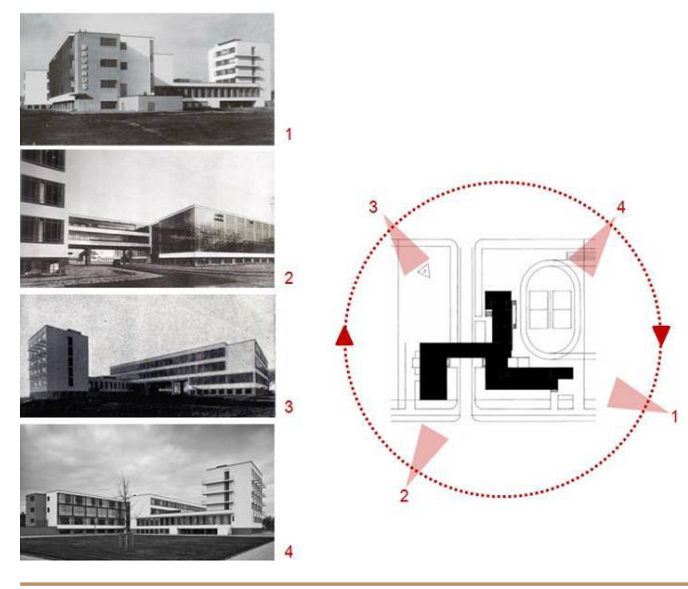

Figura 1: Walter Gropius. Bauhaus, Dessau, 1925-26. Secuencia de vistas exteriores.

Fuente: Elaboración propia (fotografías de Lucía Moholy).

\footnotetext{
2 "El ojo crea la perspectiva, la marcha la hace vivir".

3 El título del libro de Giedion remite a la obra de Hermann Minkowski Espacio y Tiempo, de 1907, que sentaba las bases matemáticas para la teoría de la relatividad de Einstein.
} 

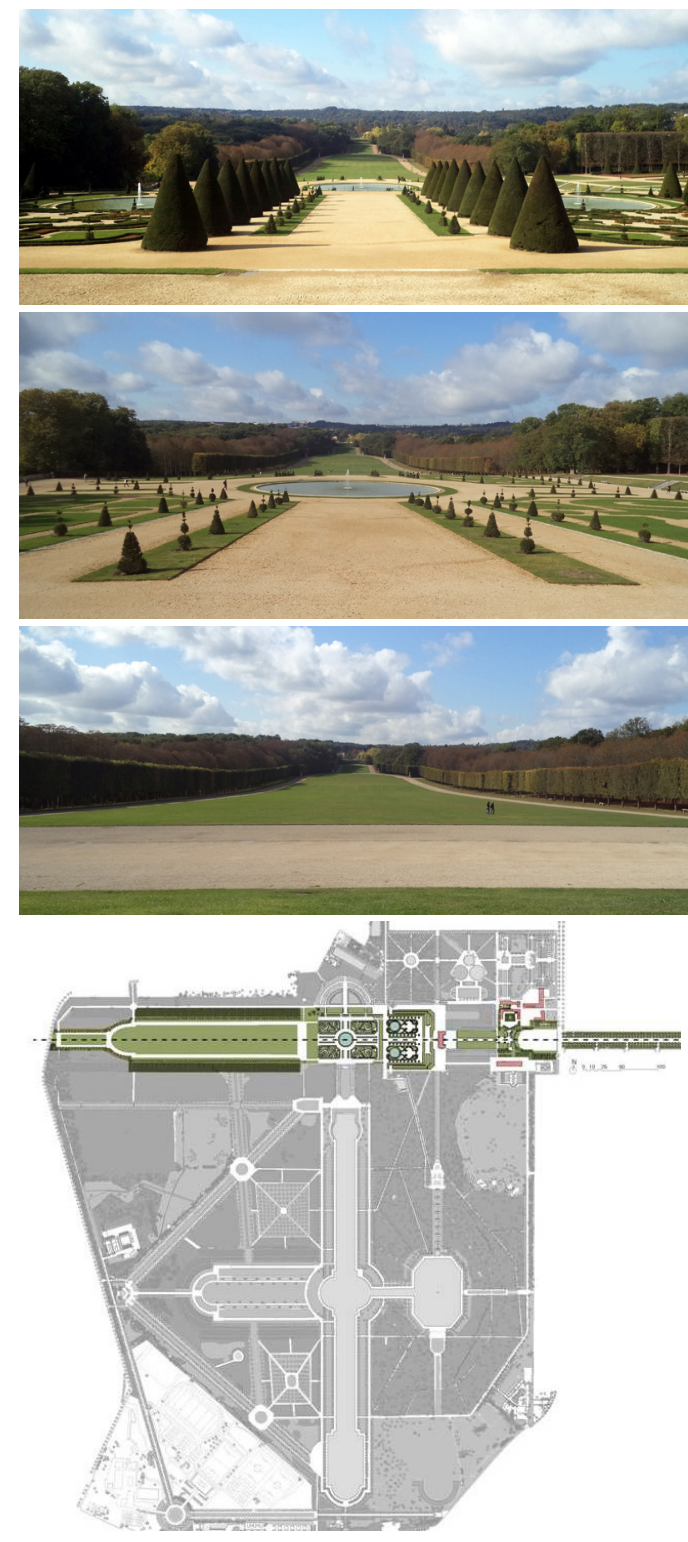

Figura 2: Jardines de Sceaux, París. Eje principal esteoeste: secuencia de perspectivas a partir del palacio.

Fuente: Dibujo: M. de los Santos. Fotografías: archivo de Javier Pérez-Igualada.

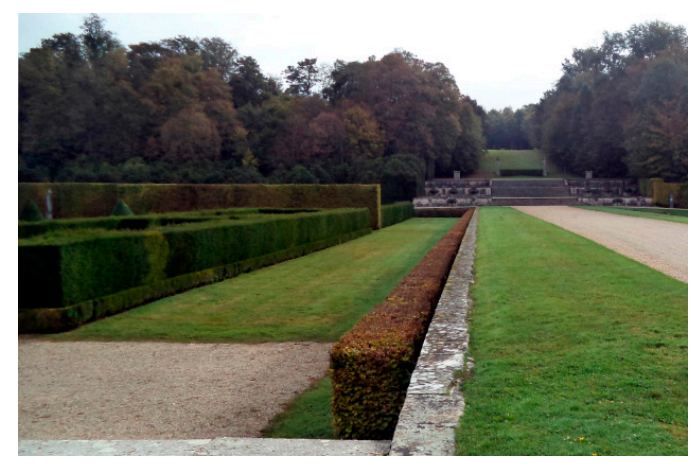

Figura 3: La mirada transversal. André Le Nôtre. Jardines de Vaux-le-Vicomte.

Fuente: Archivo de Javier Pérez-Igualada.
En otra obra de Le Nôtre, el jardín de Sceaux, e movimiento del punto de vista a lo largo del eje principal este-oeste, que arranca del Chateau, genera igualmente una serie de secuencias visuales, pero éstas, a diferencia de las de la Bauhaus, resultan más homogéneas y estáticas, porque se encuadran dentro de una perspectiva preferente o predeterminada, que es la axial, basada en un equilibrio simétrico (Figura 2).

Sin embargo, en los jardines de Le Nôtre, a pesar de la férrea disciplina visual que impone el eje principal, son posibles también otras miradas alternativas. Basta a veces con mirar a un lado, orientando la vista en transversal al eje, para descubrir perspectivas diferentes, libres de la simetría y sorprendentemente contemporáneas en su composición (Figura 3).

La mirada en movimiento se puede capturar o representar gráficamente por diferentes procedimientos. Mediante una filmación de duración igual al tiempo real empleado, es posible abarcar incluso la totalidad de lo percibido de manera continua. Lo habitual, sin embargo, es recurrir a alguna síntesis o "compresión", que permita una interpretación más directa de esa mirada, y que no requiera un tiempo igual al de la experiencia original, sino menor. Así, las filmaciones se organizan como suma de fragmentos o grupos de fotogramas, interrumpiendo, a través del montaje, la continuidad temporal de la experiencia perceptual y reduciendo así el tiempo necesario para reproducirla ${ }^{4}$.

Una síntesis gráfica que permite una compresión temporal mucho mayor, y por ello más útil, de la experiencia perceptual es la que se obtiene mediante series de fotografías, identificando en planta los diferentes puntos de vista elegidos ${ }^{5}$. Es posible también utilizar series de dibujos en perspectiva, como hacía Gordon Cullen (1971) cuando explicaba en Townscape el concepto de visión serial o Steenbergen y Reh (2001) en su análisis de los grandes jardines europeos. Como síntesis gráfica, las series de dibujos implican de hecho una depuración mayor de la experiencia perceptual original que la de las series fotográficas, ya que el dibujo es una mirada selectiva a la realidad, en la que se elige representar algunas cosas, las sustanciales, y se omiten otras.

Cada una de las imágenes individuales-sean fotográficas o dibujadas- que componen estas series equivalen a lo que se identifica con el término "viñeta" en el campo del cómic: un recuadro que representa un instante significativo de una historia contada de manera esencialmente gráfica.

Si adoptamos, consecuentemente, el nombre de viñeta para la unidad mínima de montaje necesaria para que la experiencia perceptual del paisaje resulte inteligible, entonces la sucesión de viñetas equivale a una representación gráfica sintética de la sucesión espaciotemporal (Figura 4).

${ }^{4}$ Tim Benton (1987) ha analizado con detalle las dificultades asociadas a la representación fílmica de la promenade architecturale de Le Corbusier, en las villas Stein y Savoye.

${ }^{5}$ Esta técnica es la utilizada por Frederic Gibberd (1953) para analizar las plazas italianas en su libro Town Design. 



Figura 4: Viñetas dibujadas. a) Secuencias visuales en Vaux-le-Vicomte. b) El paisaje en el cómic. Página de Nido de espías en Alpha-Plage, de Serge Clerc.

Fuente: Steenbergen y Reh (2001). Clerc (1985).

Esta síntesis gráfica mediante series de imágenes tiene un objetivo analítico-interpretativo: busca explicar una experiencia, más que reproducirla. Las series de fotografías Shortest Day de Jan Dibbets, por ejemplo, sintetizan la experiencia visual de un observador inmóvi que contempla un paisaje urbano que va cambiando con la luz a lo largo del día, y las series de los New Dutch Landscapes de Ger Dekkers (1986), por su parte, sintetizan la experiencia visual de un observador en movimiento, que se desplaza lateralmente a uno y otro lado de un eje central por delante de un paisaje estático (Figura 5).

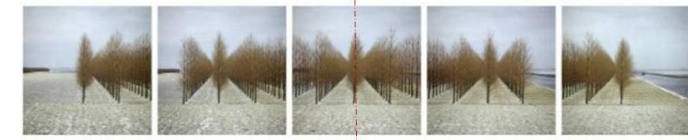

Figura 5: Ger Dekkers. Alineaciones de árboles, 1974. Movimiento de desplazamiento del punto de vista con respecto al eje central para tomar la serie de fotografías. Fuente: Elaboración propia sobre fotografía de G. Dekkers (1986).

Las series de viñetas, por tanto, son una síntesis de la percepción espacio-temporal opuesta a la que propone el cubismo para la pintura, que tiene un objetivo fundamentalmente artístico-plástico, y que consiste en superponer en una única imagen las diferentes vistas obtenidas sucesivamente por el observador al desplazarse en el espacio y en el tiempo, como ocurre en L'Arlesienne de Picasso (1911-12), o bien las vistas obtenidas por un observador fijo de un objeto en movimiento, como en el Nu descendant un escalier (1912) de Duchamp. La célebre serie de pinturas Storia di Nastagio degli Onesti (1483) de Botticelli, sería en este sentido "cubista", dado que en cada imagen se nos muestran simultáneamente las figuras de los personajes que corresponden a diferentes instantes temporales de una secuencia de acontecimientos que ocurren en un mismo paisaje arbolado (Figura 6a)
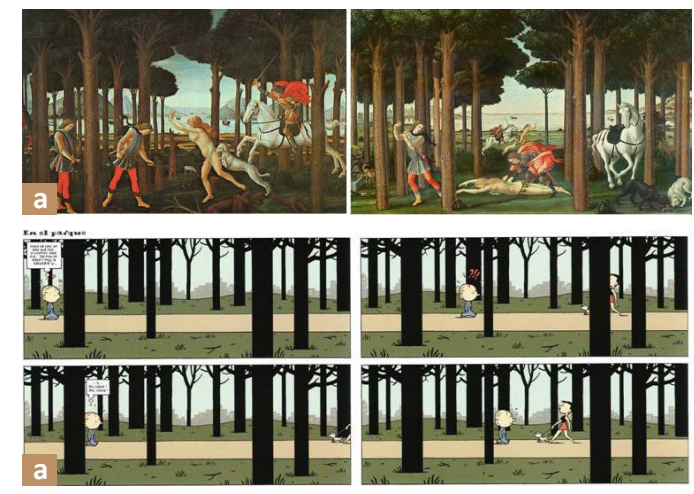

Figura 6: Aproximación proyectual a los procesos de transformación del material vegetal: transformación continua resultado del ciclo vital de crecimiento. a) Brooklyn Bridge Park, Nueva York. Michael van Valkenburgh Associates. b) Greenwich Peninsula Park, Londres. Michel Desvigne, 1997

Fuente: a) Michael Van Valkenburgh Associates (2009). b) Desvigne (2009).

\section{La aproximación proyectual.}

\section{Espacio-tiempo y procesos en arquitectura del paisaje}

El paisajismo o landscape architecture surge como disciplina proyectual, enfocada en un primer momento a la configuración de los jardines y espacios abiertos. 
Ello implica definir sus elementos inertes (terreno, muros, pavimentos, microarquitecturas, agua, etc.) y sus elementos vivos, en transformación permanente, como el material vegetal.

La transformación formal de las especies vegetales tiene dos facetas, una continua, de crecimiento o aumento de tamaño, y otra cíclica, de cambio estacional. La presencia como componente del proyecto de un material vivo como las plantas hace que los espacios verdes puedan asimilarse a lo que Umberto Eco llamaba "obra abierta", una obra que no es estática, sino que evoluciona y se transforma en el tiempo.

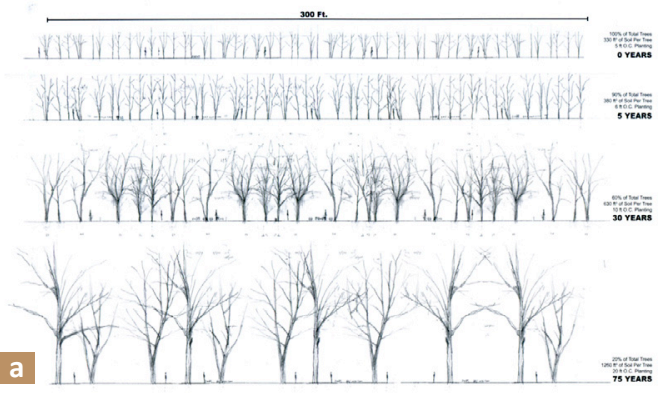

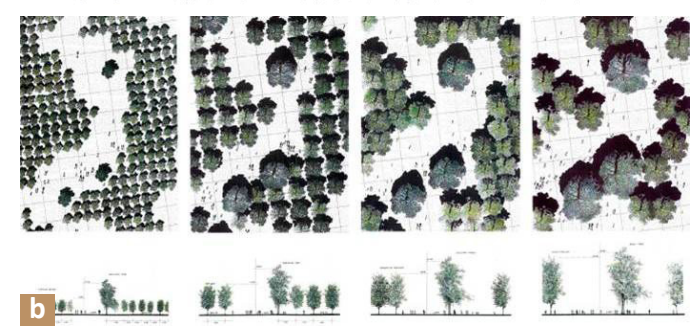

Figura 7: Aproximación proyectual a los procesos de transformación del material vegetal: transformación continua resultado del ciclo vital de crecimiento. a) Brooklyn Bridge Park, Nueva York. Michael van Valkenburgh Associates. b) Greenwich Peninsula Park Londres. Michel Desvigne, 1997

Fuente: a) Michael Van Valkenburgh Associates (2009) b) Desvigne (2009).

Para afrontar el proyecto del paisaje como obra abierta resulta de utilidad la distinción que realiza James Corner entre tres tipos de dibujo arquitectónico presentes en el campo del paisajismo. Los dos primeros tipos de dibujo son el de representación y el de notación, y están vinculados al análisis de los aspectos espaciales y temporales de la percepción paisaje. El tercer tipo, en cambio, es el dibujo de proyección, que es una herramienta para la construcción del paisaje, ya que actúa como un elemento de mediación entre la visión de diseñador, que comporta la ideación de un paisaje todavía inexistente, y la construcción efectiva del proyecto en un lugar físico real (Corner, 2014).

En la misma línea, Noel Van Dooren (2009) ha estudiado con detalle en su tesis doctoral, titulada Drawing Time (dibujando el tiempo), los modos de representar el crecimiento, el cambio y las dinámicas en la práctica profesional de la arquitectura del paisaje en Holanda desde 1985. Para la elaboración del proyecto, los paisajistas adoptan por lo general instrumentos que
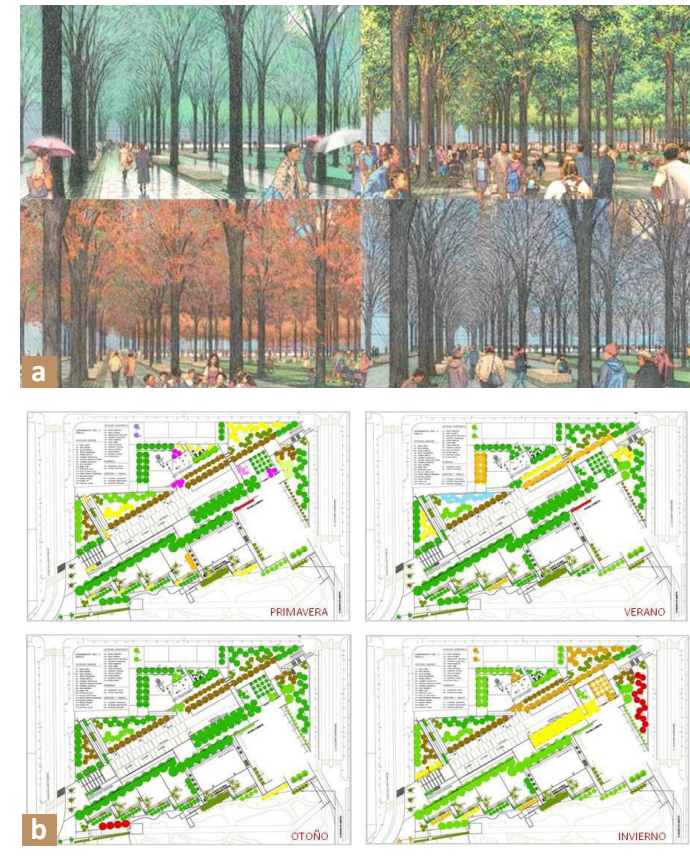

Figura 8: Aproximación proyectual a los procesos de transformación del material vegetal: transformación cíclica estacional. a) The Sacred Forest, 9-11 Memorial, Nueva York. Perspectivas en las diferentes estaciones del año. b) Ampliación del Jardín de Ayora, Valencia. Planos de variaciones cromáticas estacionales en el arbolado. Fuente: a) Walker (2005). b) Pérez-Igualada (2016)

provienen de la tradición del dibujo de arquitectura. Las plantas, secciones y perspectivas, primero, y el dibujo digital más tarde, son herramientas de prefiguración de una realidad física todavía inexistente, que permiten abordar la construcción de un edificio y también la de un jardín. Sin embargo, el edificio y el jardín son dos realidades físicas diferentes: el primero es un objeto básicamente inerte; el segundo, como hemos señalado, es un objeto en transformación ${ }^{6}$.

Sería pues deseable que la representación del paisaje en el proyecto utilizase herramientas específicas, capaces de capturar su naturaleza cambiante. Como señala Van Dooren, "Un verdadero dibujo del paisaje debería contarnos algo acerca de la evolución del paisaje en el tiempo, sus estadios intermedios y su madurez" (2013, p.10).

Las series de imágenes, que como hemos visto son un sistema adecuado para sintetizar una experiencia visual espacio-temporal, resultan adecuadas asimismo en el proyecto para anticipar experiencias espacio-temporales futuras y procesos de cambio previstos, sean naturales o inducidos.

Así, en proyectos como el de Michael van Valkenburgh Associates para el Brooklyn Bridge Park, o en el de Michael Desvigne para los espacios verdes de la

${ }^{6}$ Diana Balmori (2014) ha explorado también de un modo sistemático las formas de representación utilizadas a lo largo del tiempo en arquitectura del paisaje, y en particular las herramientas innovadoras, tanto digitales como analógicas o híbridas. 
Greenwich Peninsula en Londres (Figura 7), se diseña de un modo detallado la sucesión vegetal, y se representan mediante series de viñetas los programas de plantación, que contemplan las diferentes etapas por las que pasarán las agrupaciones de especies al crecer.

En cuanto a la representación de las transformaciones cíclicas del material vegetal, las viñetas que se requieren son lógicamente cuatro, una por cada estación del año, tal como vemos en las perspectivas del proyecto de Peter Walker para el Memorial del 11-S en Manhattan. Puede optarse también por una representación en planta de las variaciones cromáticas estacionales de cada una de las plantaciones, y en especial del arbolado (Figura 8).

En arquitectura del paisaje, las series de plantas temáticas son un desglose de los diferentes elementos del proyecto, reflejando la multiplicidad de capas que lo componen y documentando técnicamente cada una de ellas para poder abordar su construcción material.
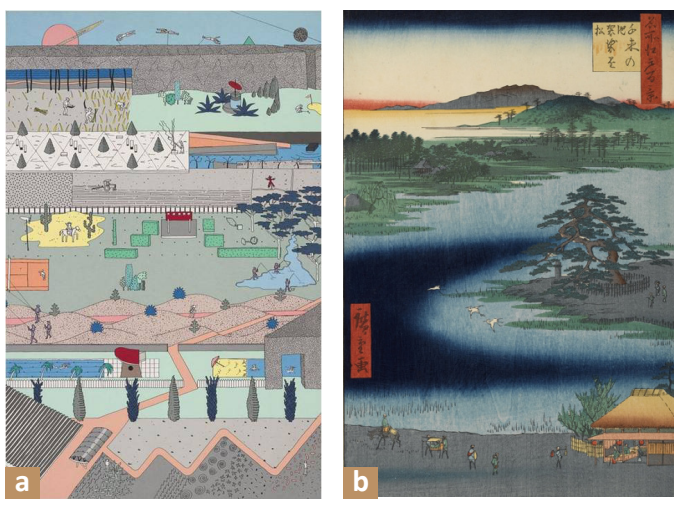

Figura 9: a) Propuesta de concurso para el Parque de la Villette. OMA (R. Koolhaas, E. Zenghelis) con M. Corajoud, 1982. b) Hiroshige. Vista de Edo.

Fuente: a) Waldheim (2016). b) Wikimedia Commons. Public Domain.
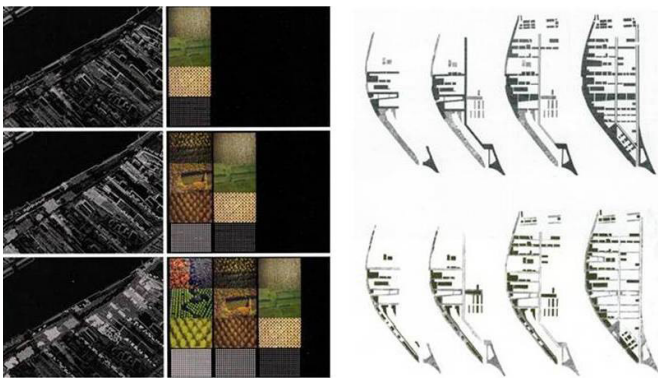

Figura 10: Michel Desvigne. Paisajes intermedios a) Propuesta paisajística para la ribera del Garona (Parc des Angèliques), Burdeos, 2012. b) Lyon Confluence, 2015. Fuente: Desvigne (2009).

Las series de plantas pueden ser también viñetas que muestran por separado las fases sucesivas de esa construcción. En ambos casos, el objetivo es el de prefigurar un único escenario futuro, que tiene unos elementos y al que se llega por etapas. El paisaje construido, señala Corner (2014), debe ser determinado con antelación, y existirá después que el dibujo, no antes ${ }^{7}$.
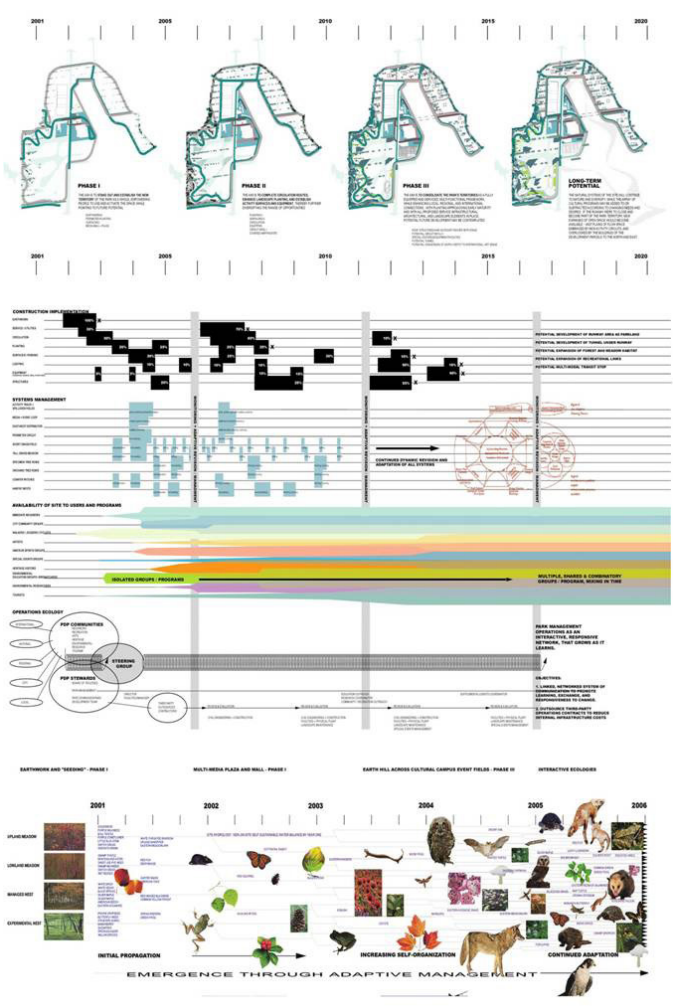

Figura 11: James Corner y Stan Allen (Field Operations), con Nina-Marie Lister. Proyecto para el concurso de Downsview Park, Toronto, 2000

Fuente: Czerniak (2001)

\section{Urbanismo desde el paisaje: el plan y la representación de la indeterminación}

El cambio principal experimentado por el paisajismo como disciplina en los últimos años del siglo XX es su posicionamiento en el territorio del urbanismo, un campo que trasciende la escala del diseño tradicionalmente asociada a la arquitectura del paisaje, y en el cual es el plan, y no el proyecto, el instrumento que permite incorporar los conceptos de complejidad, incertidumbre y cambio derivados del nuevo paradigma ecológico.

Este posicionamiento se apoya en la línea abierta a finales de los años 90 por el Landscape Urbanism, un término acuñado por Charles Waldheim para designar un urbanismo orientado desde el paisaje que, extrapolando a la ciudad las técnicas del planeamiento ecológico propuestas por McHarg para entornos naturales, busca desarrollar una ecología espacio-temporal integral, en la que el entorno urbano y el mundo "natural" no sean realidades disociadas (Waldheim, 2016).

7 "The built landscape must be determined in advance, and will exist after the drawing, not before it" (Corner, 2014, p. 164). 
Uno de los rasgos que caracterizan este movimiento es precisamente la concepción del proyecto como entendimiento de los procesos en el tiempo (Corner 2006). Con ello, la aproximación proyectual a la cuestión de la relación entre espacio, tiempo y paisaje da un salto de escala y adquiere una dimensión más estructural, lo que favorece a su vez la aparición de nuevas herramientas gráficas. Un claro antecedente de este enfoque es el proyecto presentado en 1982 al concurso para el Parque de La Villette en París por OMA (Rem Koolhaas y Elia Zenghelis), con la colaboración del paisajista francés Michel Corajoud. En esta propuesta se aborda el proyecto del paisaje desde una perspectiva entonces inhabitual, en la que el centro de gravedad se desplaza desde el diseño hacia la ecología, y la definición de formas pierde importancia frente a la definición de procesos. El proyecto de OMA, en concreto, propone un esquema de franjas como soporte para diferentes $e$ impredecibles usos futuros, explorando las posibilidades que abre la indeterminación, la yuxtaposición de relaciones imprevistas entre las diversas superficies y programas del parque. Para representar gráficamente esta indeterminación, OMA recurría a diagramas en planta y sección, así como a un singular dibujo en perspectiva, que muestra pequeñas figuras en el paisaje dedicadas a diversas actividades, y recuerda a algunas de las vistas de Edo de Hiroshige (Figura 9)

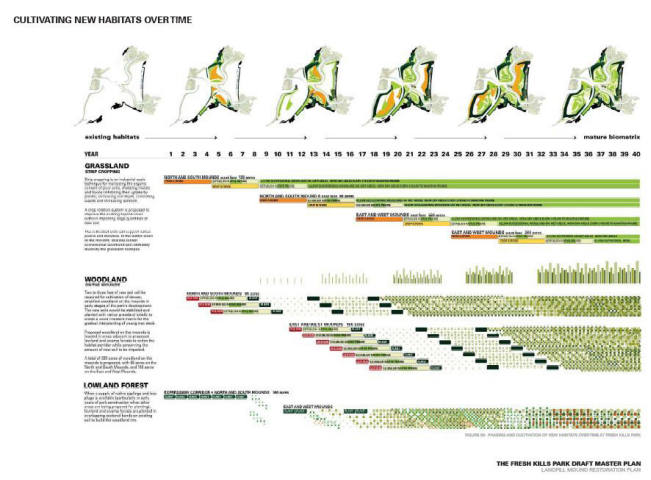

Figura 12: James Corner Field Operations. Fresh Kills Park, Nueva York, 2006.

Fuente: www. freshkillspark.org: Fresh Kills Park Draft Master Plan.

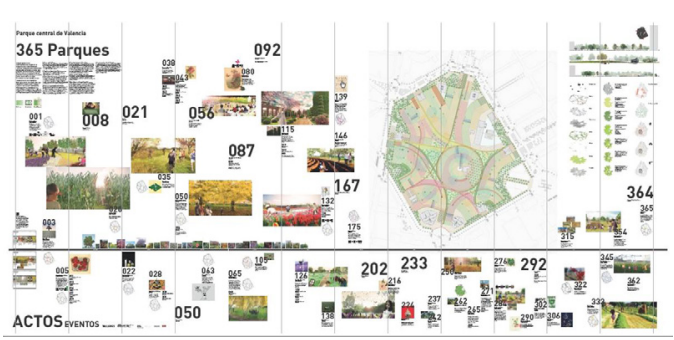

Figura 13: Foreign Office Architecture + AICEquip-GPOAA. Propuesta para el concurso de Parque Central. Valencia (España), 2011

Fuente: www. valenciaparquecentral.es

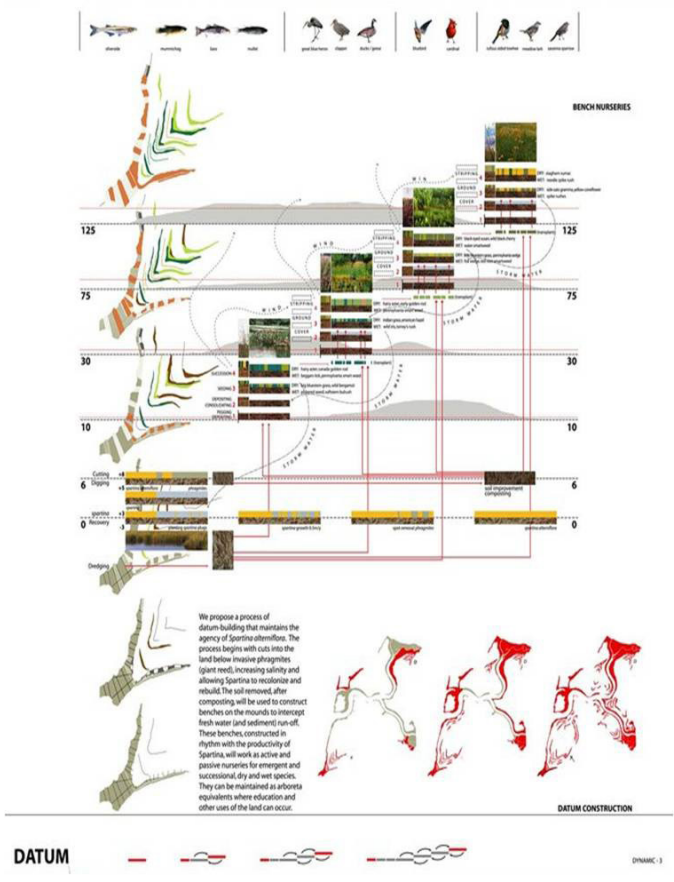

Figura 14: Anuradha Mathur y Dilip da Cunha. Dynamic Coalition. Fresh Kills Landfill, Staten Island, NY (con Tom Leader Studio).

Fuente: www.mathurdacunha.com

Michel Desvigne, por su parte, ha explorado también sistemas de representación acordes con el objetivo de diseñar la evolución espacio-temporal del paisaje en su conjunto, con sus etapas intermedias. Así, en sus proyectos para la ribera del Garona en Burdeos, Lyon Confluence o Summer Park en Governors Island (Figura 10), Desvigne propone un sistema de planimetrías múltiples de los componentes o estratos en evolución (bosques, rotación de cultivos, praderas, caminos, etc.), utilizando para cada uno de ellos bloques de dibujos temáticos. Y en lugar de dibujar series de planos temáticos que conforman un supuesto estado final definitivo de cada estrato del proyecto, se elaboran series de planos más "desdibujados", que prefiguran procesos de transformación que se suceden en el tiempo, y permiten representar lo inacabado (Desvigne, 2009) ${ }^{8}$.

James Corner, destacado representante del Landscape Urbanism, ha explorado en su práctica profesional formas diversas de representación de esta ecología espaciotemporal, con proyectos tan influyentes como los de los concursos para Downsview Park en Toronto (Figura 11) y Fresh Kills Park en Nueva York. Además de las viñetas, que adoptan la forma de series de plantas temáticas, mostrando las capas y fases sucesivas de los procesos de transformación del lugar, en estos proyectos se utilizan otros recursos gráficos innovadores, como son los diagramas de barras o las matrices espacio-temporales, que explican la evolución prevista -o propuesta- de los hábitats animales y los sistemas hidrológicos, además de la sucesión vegetal (Figura 12).

${ }^{8}$ Desvigne se inscribe en una línea de pensamiento próxima a Gilles Clément (1991) y su concepto de Jardín en Movimiento. 
Un enfoque similar puede encontrarse en la propuesta de Alejandro Zaera (Foreign Office Architecture) para el concurso del Parque Central de Valencia (Figura 13), titulada 365 parques, que está planteada no tanto como una ideación de formas, sino como un diseño de una agenda o programa socio-funcional, integrado por una sucesión de eventos de ocio y educativos para todos los días del año que se inspiran en los ciclos y procesos de la agricultura.

Profundizando en esta línea, Anuradha Mathur y Dilip da Cunha desarrollan, en proyectos como el del concurso para el Fresh Kills Landfill, unas cartografías analíticas dotadas de una gran carga conceptual, cuya belleza gráfica corre paralela a una cierta dificultad de lectura por su alto grado de abstracción. Las cartografías analíticas, en cualquier caso, son una herramienta cada vez más utilizada en paisajismo por su capacidad para abordar la representación de procesos abiertos complejos (Figura 14).

Dentro de las cartografías analíticas, un instrumento de uso cada vez más frecuente para explorar las posibilidades que abre la indeterminación, mostrando gráficamente una multiplicidad de posibles escenarios futuros alternativos, son las perspectivas axonométricas conceptuales, que en el plan estratégico Detroit Future City, de Stoss, son la herramienta de representación preferente de ese futuro incierto, complementadas con diagramas de flujos (Figura 15)

Estas herramientas de representación pueden combinarse con otras, como el modelado 3D o el video digital, con el que ha experimentado ampliamente

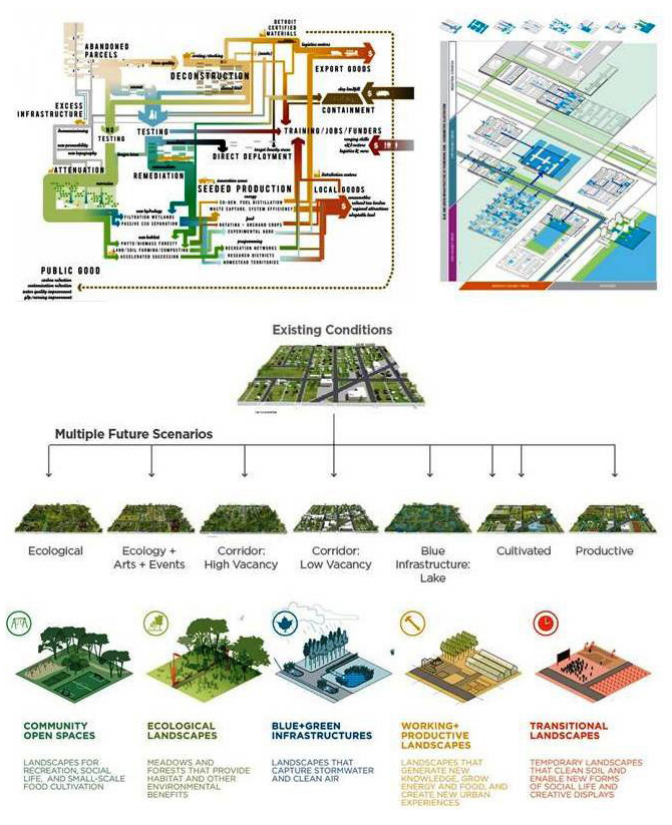

Figura 15: Stoss Landscape Architects. Detroit Future City. Plan Marco Estratégico, Detroit Works Project. Fuente: www.stoss.net
Christophe Girot (2006) por considerarlo de utilidad tanto para el proyecto como para el análisis, ya que contribuye a una mejor integración de la parte creativa del proceso de diseño y de la relativa a su comunicación pública.

\section{Conclusión}

La espacialidad y la temporalidad son dos aspectos intrínsecos e indisociables del paisaje, tanto en la experiencia perceptual como en la aproximación al mismo desde el proyecto, a todas las escalas.

Desde una perspectiva dual, en la que analizamos por separado los aspectos perceptuales y los proyectuales, hemos examinado en este trabajo algunas herramientas de expresión gráfica especialmente significativas por su potencial para representar las morfologías del cambio. En concreto, se ha estudiado el papel de estas herramientas en el análisis de los espacios abiertos primero, y en la práctica proyectual asociada a la arquitectura del paisaje a continuación.

Las series de imágenes y de planos temáticos, como hemos podido comprobar a través de referentes relevantes de la práctica profesional, son un sistema adecuado para sintetizar una experiencia visual espaciotemporal, y también para anticipar en el terreno del proyecto experiencias espacio-temporales futuras y procesos de cambio. El dibujo es en esa práctica proyectual de la arquitectura del paisaje una herramienta de reflexión y de análisis, pero también, y sobre todo, una actividad propositiva. Como tal, actúa como visor o catalizador de ideas, representándolas de modo que sea posible llevarlas a la realidad mediante procesos de construcción que estarán a cargo de agentes distintos al proyectista.

Finalmente, hemos mostrado el modo en que la expresión del espacio-tiempo, el movimiento y la transformación, se abordan en el pensamiento visual contemporáneo acerca del paisaje desde un enfoque que da primacía al plan (la estrategia) frente al proyecto (el diseño). Este cambio de enfoque va asociado a un salto del paisajismo de la escala arquitectónica a la urbanística, resultante del desplazamiento de su centro de gravedad desde un paradigma estético a otro ecológico. Este salto disciplinar y de escala tiene importantes consecuencias en cuanto a los sistemas de representación, ya que un plan de estrategias y un proyecto de formas requieren ser expresados a través de herramientas gráficas muy diferentes, entre las que se encuentran los sistemas de planimetrías múltiples, las matrices espacio-temporales y las cartografías analíticas.

Cómo citar este artículo/How to cite this article: Pérez-Igualada, J., y Vicente-Almazán, G. (2020). Espacio, tiempo y paisaje. La representación de procesos y experiencias visuales en el análisis, el proyecto y la planificación de los espacios abiertos. Estoa. Revista de la Facultad de Arquitectura y Urbanismo de la Universidad de Cuenca, 9(17), 31-39. doi: 10.18537/est. v009.n017.a03 


\section{Referencias bibliográficas}

Balmori, D. (2014). Drawing and Reinventing Landscape. Londres, Reino Unido: John Wiley \& Sons.

Benton, T. (1987). Le Corbusier y la promenade architecturale. Arquitectura, 264, 38-47.

Bigas Vidal, M.; Bravo Farré, L. y Contepomi, G. (2010) Espacio, tiempo y perspectiva en la construcción de la mirada arquitectónica contemporánea: de Hockney a Miralles. Expresión Gráfica Arquitectónica, 15 (15), 128 137. doi: 10.4995/ega.2010.1000.

Clément, G. (1991). Le Jardin en mouvement. París, Francia: Pandora.

Clerc, S. (1985). Nido de espías en Alpha-Plage. En S. Clerc, La noche del Mocambo. Barcelona, España: Metal Hurlant.

Corner, J. (2006). Terra fluxus. En Ch. Waldheim (Ed.) The landscape urbanism reader (pp. 21-32). New York, Estados Unidos: Princeton Architectural Press.

Corner, J. (2014). Drawing and Making in the Landscape Medium. En J. Corner, Landscape Imagination: Collected Essays of James Corner 1990-2010 (pp. 161-196). New York, Estados Unidos: Princeton Architectural Press.

Cullen, G. (1971). Townscape. Londres, Reino Unido: Architectural Press.

Czerniak, J. (2001). CASE-Downsview Park Toronto Cambridge, Mass., Estados Unidos: Harvard University, Graduate School of Design.

Dekkers, G. (1986). New Dutch Landscapes. Amsterdam, Países Bajos: Waanders.

Desvigne, M. (2009). Intermediate Natures. The Landscape of Michel Desvigne. Basel, Suiza: Birkhäuser.

Gibberd, F. (1953). Town Design. Nueva York, Estados Unidos: Praeger.

Giedion, S. (1941). Space, Time and Architecture. New York, Estados Unidos: Harvard University Press.

Girot, C. (2006). Vision in Motion: Representing Landscape in Time. En Ch. Waldheim (Ed.), The landscape urbanism reader (pp. 87-103). New York, Estados Unidos: Princeton Architectural Press.

Michael Van Valkenburgh Associates (2009). Reconstructing Urban landscapes. New Haven, USA y Londres, Reino Unido: Yale University Press.

Morán, P. (2014). Morfologías del cambio: la representación de procesos en el proyecto de paisaje. En VISeminario Internacional de Investigación en Urbanismo, Barcelona-Bogotá. Barcelona, España: Departamento de Urbanismo y Ordenación del Territorio.
Pérez-Igualada, J. (2016). Arquitectura del paisaje Forma y materia. Valencia, España: Editorial Universidad Politécnica de Valencia.

Steenbergen, C. y Reh, W. (2001). Arquitectura y paisaje: la proyectación de los grandes jardines europeos. Barcelona, España: Gustavo Gili.

Van Dooren, N. (2009). Drawing Time. The representation of growth, change and dynamics in Dutch landscape architectural practice after 1985. Amsterdam, Países Bajos: Universidad de Amsterdam.

Van Dooren, N. (2013). Reflexiones sobre representación. Paisea, (27), 4-12

Waldheim, Ch. (2016). Landscape as Urbanism: A General Theory. New York, Estados Unidos: Princeton Architectural Press.

Walker, P. (2005). Peter Walker and Partners: landscape architecture: defining the craft. Londres, Reino Unido: Thames \& Hudson. 